\title{
1. An appraisal of the EU Directive on Trade Secrets
}

\author{
Jens Schovsbo, Timo Minssen and Thomas \\ Riis $^{1}$
}

The EU Trade Secrets Directive ('the Directive') ${ }^{2}$ has standardized EU member states' national laws on the protection of trade secrets. For the first time, a harmonized definition of what constitutes a 'trade secret' is established, as well as common measures aimed at preventing the misappropriation of trade secrets and rules for procedures and sanctions.

The adoption of the Directive reflects the growing importance of trade secrecy protection internationally. Trade secrets offer protection even for knowhow and business information that cannot be protected by conventional intellectual property rights (IPRs). This could, for instance, be an invention that does not fulfil the requirements to obtain patent protection, such as the eligibility, novelty or nonobviousness criteria or nontechnical business information such as price or customer information. Another advantage of trade secrets is that the protection can in principle last in perpetuity, while conventional types of IPRs offer protection only for a limited period of time. Since it is not the information as such which is being protected, the trade secret holder cannot, however, object to the fact that a third party independently develops identical products, processes, algorithms and so on. Protection lapses as soon as the information protected as a trade secret becomes publicly available or loses its commercial value. As is well known from IPRs, protecting information comes with strings attached.

National experiences have shown that protecting trade secrets may give rise to special concerns about defining the protectable subject matter and the scope of the protection. One example includes the many instances where secrets are being developed or used as part of an employment contract. Here an overly

1 We warmly thank student assistants Bénédicte Illien, Dimitrios Svolis, Nicolai Stig Hallander Hansen, CeBIL and Ulrika Skadhauge, CIIR, for their valuable help.

Directive (EU) 2016/943 of the European Parliament and of the Council of 8 June 2016 on the protection of undisclosed know-how and business information (trade secrets) against their unlawful acquisition, use and disclosure, [2016] OJ L 157/1. 
broad conception of what constitutes a 'secret', for example to cover the normal skills of the particular trade or a broad scope of exclusivity, may limit employee mobility. These concerns are going to magnify in the light of the EU objectives of furthering and securing the free movement of labour. In the same vein, concern has been raised that secrecy protection may impede on the ability of whistleblowers to document irregularities in companies (and for media to report on such events). Other contentious issues include public institutions. For such institutions (notably universities), protecting secrets and engaging in contracts with private companies (PPP) is going to give rise to problems not just regarding the practicalities but also on a more fundamental level, as the very notion of keeping information 'secret' may be hard to incorporate into existing cultures based on openness and transparency.

The Directive constitutes the skeleton of the new EU protection system. The muscles, arteries, and so on that are going to create a body of EU trade secrets law will develop in the coming years at the intersections between the Directive, the national experiences and the diverse needs of users and society in general. It is for this reason that the contributions in this book cover a broad range of areas. Part I provides the general framework for the Directive and puts trade secrecy protection in context with other broader areas of law, such as information law and international law. Part II turns to the implementation of the Directive in the Nordic countries, Germany, the United Kingdom, Spain and Portugal. Next, Part III deals with more specific issues that emerge at the interface of trade with other areas of the law, such as the challenges and opportunities that can be expected with regard to employee mobility, choice of law or specific legal frameworks for enforcement of rights and data transfer. Finally, Part IV provides an overview of how specific sectors are affected by the trade secrets regime, including a detailed and technical analysis of various areas of medical applications.

Turning to Part I on the general framework, Jens Schovsbo provides a general introduction to the Directive and describes the legislative process leading to the Directive and the general principles of EU law that govern the transposition of the Directive into national law. Next, Henrik Udsen, Jens Schovsbo and Berdien van der Donk describe and analyse trade secrets as an 'information right'. As the Directive provides trade secret owners with a right to prohibit others from accessing, sharing and using trade secrets in certain situations which is related to other rules on information rights such as intellectual property rules, data protection rules and rules on protection of personality, this chapter argues that inspiration for the interpretation of the Directive can be found in those other areas.

The EU provisions on secrecy are part of a more general trend in international law to protect trade secrets. This trend arguably began in the United States, and US law continues to offer important insights into the background 
for the development of the protection system and examples of the pro and cons of protection. In her chapter on US law, Sharon Sandeen provides a US perspective on the EU rules and describes what motivated the adoption of new protection in the US. She also uses the EU system to offer a comparative perspective on US law and in this way illustrates how the fact that the EU now 'speaks with a common voice' in this area may also affect the way trade secrets protection develops internationally.

Part II looks at the implementation of the Directive into national laws. Since EU directives need to be transposed into national law in order to become effective (that is, to create rights and duties between private parties), the implementation of the rules in the Directive into national Acts is central for the actual effects of protection in the EU countries. Writing on the Nordic countries, Jens Schovsbo and Niklas Bruun describe how Denmark, Finland, Norway and Sweden have all adopted special Acts on the protection of trade secrets. Interestingly, the Acts vary on important points. The Swedish Act, for instance, does not follow the definition of 'trade secrets' found in the Trade Secrets Directive; the Finnish Act has continued the protection for entrusted drawings and models; and the Danish Act has not expressly implemented the provisions on the right to freedom of expression or disclosure for the public, and on employee mobility. In his chapter on Germany, Ansgar Ohly similarly points out how the German Act, while mostly following the Directive closely, differs at some points from the EU norm, such as on the central issue of the definition of what constitutes a 'trade secret'. The picture is the same in the United Kingdom, as described by Tanya Aplin, who points out that even though the UK government has generally made a good faith effort to implement the Directive there are also important differences, such as in the definitions of what constitutes lawful or unlawful use. In the last chapter in this part of the book, on Portugal and Spain, Ana Nordberg and Barbara Diaz Alaminos likewise conclude that the implementation of the Directive has resulted in extensive changes but also note that in some respects further clarification of the Directive by national courts and the CJEU, as well as further legislative initiatives, are needed.

As can be seen from this brief overview of the chapters in Part II, a common picture emerges: the national Acts have led to 'harmonization' but not to 'uniformication' of the area. Despite the common starting point in the form of the lengthy and detailed provisions of the Directive, important differences remain. These seem at times to be the unforeseen or unwanted effects of attempts to align traditional ways of dealing with trade secrets with the requirements in the Directive. At other times, the national legislators have decided with open eyes to disregard obligations following from the Directive. Eventually, many of these discrepancies will be ironed out by the CJEU. Now, however, the level of variation seems to be relatively high. 
Having introduced the Directive and described its implementation into national law, Part III of the book turns to some of the specific issues with which courts and decision makers will be confronted as they seek to put flesh on the bones provided by the Directive. As the first specific issue, Bengt Domeij examines the relationship between trade secrets and employee mobility and explores what the Directive may entail for the tradeoff between employee freedom and corporate control of trade secrets. The protection afforded to trade secrets under the Directive is not affected by the termination of an employment. Ex-employees can, therefore, be seen as unlawfully using trade secrets and as being in breach of a confidentiality agreement or any other duty not to disclose a trade secret. Nothing in the Directive shall be understood to offer any ground for restricting employees' use of experience and skills honestly acquired in the normal course of their employment. In a 2015 proposal from the European Parliament to amend the Directive, it was suggested that employees' honestly acquired information should also be excluded. This was not accepted. For EU countries such as Sweden, which have traditionally had a liberal attitude towards ex-employees' use of trade secrets that have been acquired in honest performance of duties, the wording may pose difficulties in the balancing of employee mobility and maintenance of trade secrets and employees.

Rochelle Dreyfuss and Mireille van Eechoud analyse choice of law questions in trade secrecy cases. As trade secrecy has become a widespread strategy for appropriating returns from innovation, problems related to globalization have come to the fore. The preamble of the Directive suggests that the Directive was enacted in recognition of potential crossborder problems. While it attempts to reduce inconsistencies among the protective regimes of member states, it falls far short of harmonizing the law. Furthermore, experience in the United States suggests that many of the concepts used in the Directive are susceptible to multiple interpretations. Examples include 'use of experience', 'generally known', 'commercial value' and 'reasonable steps'. But despite the likelihood of divergence, the Directive does not include a choice of law rule and it is not always evident how rules from existing instruments on applicable law would apply. Using the US experience and drawing on EU choice of law for other forms of intellectual property, this chapter offers views on the approach EU adjudicators should take to resolving transnational trade secrecy disputes.

Moving to the next specific issue, Ana Nordberg analyses trade secret protection for big data. She examines the Directive from a technologically informed legal perspective, looking at the possibilities and scope of protection that the Directive offers for knowledge based activities and business models. Asymmetries in information are a fundamental transaction cost and in this sense, informational quality and quantity translate into economic competitive advantage. Different types of informational resources have long been an 
important asset for businesses. Informational technologies, automated data retrieval and cross-referencing will produce large quantities of valuable data that can be used for research, development and marketing of all types of products and services. Big data is not static data, it is real time data, searchable and able to produce new data. Such data will constitute an important immaterial asset and trade secrets an important form of legal protection. However, and as a reverse side of the coin, artificial intelligence and data mining tools pose a huge challenge to trade secrets as a legal concept.

The Directive contains provisions on the enforcement of rights in trade secrets. In his chapter, Thomas Riis examines the enforcement provisions of the Directive and compares them to the similar provisions in the Directive on Enforcement of Intellectual Property Rights. Even though the enforcement provisions of the Directive are modelled upon the Enforcement Directive, some new measures have been introduced (and others have been omitted). By way of example, the Directive introduces (a) an explicit provision on applications concerning the unlawful acquisition, use or disclosure of a trade secret which is manifestly unfounded and where the applicant is found to have initiated the legal proceedings abusively or in bad faith; (b) provisions on limitation periods; (c) a list of specific conditions that shall be taken into consideration when granting provisional and precautionary measures and injunctions and corrective measures; and (d) a limitation on the liability for employees' damages towards their employers for the unlawful acquisition, use or disclosure of a trade secret of the employer where they act without intent.

Finally, Part IV focuses on specific sectors, and on the biomedical area, where potential tension and conflicts are expected to crystallize. In their chapter, Jacob S. Sherkow and Timo Minssen analyse how the Directive particularly affects scientists and other stakeholders that work with Adaptive Immunoreceptor Repertoir (AIRR) technology. The authors conclude that their case study on AIRR-seq data under the Trade Secrets Directive is informative about problems in the law concerning disclosure and secrecy, but they also identify opportunities and suggest best practices for implementing trade secrecy for crossborder AIRR projects. In their view, AIRR-seq data shows that it is at least theoretically possible to simultaneously promote information sharing while reserving the most value for aspects of that information to encourage private development of new technologies.

Next, Nari Lee examines the interplay of trade secrets and artificial intelligence in personal medicine, as well as the challenges that emerge from it with regard to specific areas of law such as the GDPR and the Biotechnology Directive. The author warns that the combination of development in the technological sectors, use of AIs in biomedicines and legal changes, restrictive patent eligibility, genetic privacy and expansive trade secrets protection could lead to underuse of valuable biomedical data, which may result in a new 
type of tragedy of the anticommons. The chapter concludes by revisiting the relationship between trade secrets and patent rights and suggests that it may be necessary to introduce additional regulatory measures to mandate ethical disclosure of algorithms for public policy.

In this part's final contribution, Neethu Rajam focuses on the application of the Directive to public sector biomedical research in Europe. The author first examines the arguments for applying a trade secret model in genomic research. Next, she explores the issues of public sector health research and the application of trade secrets law as an emerging alternative to open biotechnology. Finally, the chapter analyses the alternative limitations in Europe that may possibly limit the application of trade secrets such the Public Sector Information Directive. The author argues that trade secrets could be considered as an alternative mechanism which could uniquely enable the balancing of protection of information and sharing of biomedical data in the interest of research and development.

As the contributions to this book have demonstrated, the impact of the new Directive is deep and broad, and it will be felt in a wide variety of complex sectors. In that regard it seems important for us to emphasize that the directive on trade secrets not only gives rise to many challenges but, in addition to enhancing EU wide harmonization in an increasingly important area of law, also offers a broad range of mechanisms and new opportunities, which - if correctly employed - could help to strengthen our innovation system. Another challenge that relates to this is the increasing need for more global convergence in incentivizing, protecting and distributing knowhow and innovation and providing a fair basis for global competition. How exactly this shall be best achieved will remain a primary and exciting task of legal research. We believe, however, that this book will contribute to this wider debate, by demonstrating that trade secrets protection will be an increasingly important factor that should be carefully considered in any innovation research and practice. 